\title{
Conditions for photovoltaics deployment in the UK: the role of policy and technical developments
}

\author{
Chiara Candelise $*^{\mathrm{a}}$, Robert Gross ${ }^{\mathrm{a}}$, Matthew A. Leach ${ }^{\mathrm{b}}$ \\ ${ }^{a}$ Imperial College Centre for Energy Policy and Technology (ICEPT), Imperial College London, Centre for Environmental \\ Policy, Exhibition Road, SW7 2AZ London \\ ${ }^{\mathrm{b}}$ Centre for Environmental Strategy, The University of Surrey, Guildford, GU2 7XH, UK \\ *Corresponding author: c.candelise05@imperial.ac.uk
}

\begin{abstract}
The article discusses the conditions necessary to foster photovoltaic (PV) technologies deployment within the UK electricity sector. It explores the incentives to invest in PV technologies by assessing the financial viability of PV system investments in the UK. The analysis focuses on a set of target PV technologies and applications for the domestic sector. It firstly provides a picture of profitability and incentives to invest in the targeted PV systems under current UK market, technical and regulatory conditions. Then it looks at the role of policy and potential future technological development by exploring the impact of alternative policy instruments and technology cost reductions on the financial viability of investing in PV. The analysis shows that domestic PV investments are generally not profitable under current cost, market and regulatory conditions. Initial capital costs are too high and the current policy framework is not enough to make PV systems financially viable. The introduction of high enough feed in tariffs as well as the achievement of target cost reductions would make PV systems financially attractive and likely increase PV deployment in the UK.
\end{abstract}

Keywords: photovoltaic, microgeneration, United Kingdom, renewable energy policy, investment appraisal, cost reductions

\section{Introduction}

In the last decade PV sector has experienced an unprecedented growth [1, 2]. Market stimulation policies implemented in countries such as Japan and Germany have boosted the demand for PV system and the installed capacity is dramatically increasing. Moreover, the enthusiasm for solar power is spreading and more countries have implemented electricity buyback guarantee programs which are further fostering the PV sector development. Compared to other European countries UK PV market is still modest mainly due to lack of funding in terms of both demand pull and supply push policies [3]. Although it is undeniable that solar technologies have higher potential in sunnier southern Europe climate, PV has been often 
dismissed for UK deployment on the basis of a widespread misconception that the national solar radiation level is not sufficient to reach acceptable economic profitability of PV systems. However, PV sector might still play a role in UK and increase its share in the national energy mix. The high growth of PV sector in Germany, which has similar solar resource to the UK's, is first evidence in support to this statement. It is therefore interesting to explore which conditions would be needed to foster PV market in the UK.

\section{Methodology and Data}

The focus of the paper is on the domestic sector, within which target PV applications and module technologies are: standard roof top and two Building Integrated (BIPV) PV system types - PV roof tiles and glass-glass PV; crystalline silicon, a-Si (triple junction) and CIS are the PV module technologies considered. For each PV system type a stream of costs and revenues for 25 years life time of a representative $2 \mathrm{kWp}$ PV system are identified and used in the discounted cash flow analysis.

The nominal discount rate is set at $12 \%$ in line with those generally used in the business sector for less mature power generation technologies [4-7]. It is quite a strong assumption, as individual discount rates generally differ from market rates and those used by firms. Defining a "representative" nominal discount rate for the domestic sector is not straightforward. Economic and experimental economic research have shown that identifying individual's discount rates is rather difficult as they are sensitive to socio-demographic characteristics of individuals and often differ from generally observed market rates. In the case of domestic energy investment decisions, for example, they result from a combination of factors affecting energy investment decisions, including the household energy consumption patterns, income levels or more general income allocation decisions $[8,9]$. Moreover, domestic end users do not generally use discounted cash flows (and discount rates) explicitly in their purchasing decisions, but simply look at payback of the investment. In fact, their investment decisions depend on a range of other factors, including uncertainties and risks, imperfect information and lack of access to capital. In particular, domestic sector PV investment decisions are often discouraged by high upfront costs and evidence also suggests that currently in the UK the majority of domestic PV system investments are mainly driven by ideological reasons rather than pure economic analysis [10].

However, the use of discounting in this analysis seems appropriate as it helps in shedding some light on the attractiveness of domestic PV system investments, which are likely to gain 
more interest as costs go down and investment profitability increases. In addition, cash flow analysis does constitute the basis for the development of dedicated credit lines offered by credit institutions for PV, which are an effective solution to overcome the high capital cost obstacle (and are actually being offered by banks in countries with more developed PV markets and operational FIT schemes ${ }^{1}$ ). Domestic installations may also be made and financed together as an energy service package by a third party company. However, to account for the above mentioned uncertainties sensitivity analysis is done on this input assumption for higher and lower levels of discount rates, from $6 \%^{2}$ up to $20 \%{ }^{3}$.

A full discounted flow analysis should be based on annual cash flow after tax. For the purpose of this paper the effect of taxation is ignored, since the target PV sector is residential ${ }^{4}$. However, as has been argued already [7], the economics of investing in smaller domestic PV systems would probably be different if domestic generators could benefit from the more favourable fiscal treatment granted to business investors (such as enhanced capital allowance).

\subsection{Costs}

Costs included in the analysis are initial capital cost and operating and maintenance -O\&Mcosts, main component of which is the inverter replacement. O\&M costs are set at $1 \%$ of initial capital cost $[4,7,14]$. However, it must be said that most UK installers interviewed do not generally include O\&M costs in their calculations, while others suggested very cheap inverter replacement options.

For initial capital cost data the aim is to use price figures for turnkey PV systems in the UK, differentiated as much as possible between different system types and sizes as well as module technologies. This is in order to produce a robust analysis of how real system installation

\footnotetext{
${ }^{1}$ e.g. In Italy, since implementation of feed in tariffs in 2006, banks have started to offer PV dedicated financial products. The GSE, the Italian authority managing the FIT programme "Conto Energia", has also recently officially authorised the direct transfer of the revenues coming from the incentives to the financing bank. http://www.grtn.it/ita/fotovoltaico/IlfinanziamentoImpianto.asp

${ }^{2}$ Reflecting market rates.

11. Bank of England, Statistical Interactive Database - Interest \& exchange rates data in Available at: http://www.bankofengland.co.uk/mfsd/iadb/index.asp? Travel $=$ NIxIRx\&levels $=1 \& C=D Q Y \& C=K T \& C=5 T T \& C=E$ $30 \& C=E 76 \& C=E 7 B \& C=E 80 \& C=D U S \& A 4062 X B M X 4051 X 4052 X 4053 . x=5 \& A 4062 X B M X 4051 X 4052 X 4053 . y=$ $8 \&$ FullPage $=X 4051 \&$ FullPageHistory $=X 4051 \&$ Nodes $=X 4051 X 4052 X 3687 X 3691$ X4053X4058\&SectionRequired $=I \&$ HideNums=-1 \&ExtraInfo=true\#BM. Accessed: March 2009. 2009.

${ }^{3}$ Such higher levels of discount rates are in line with those often used in the literature for domestic energy efficiency modelling, as for example in the UK Markal energy system model 12. Anandarajah, G., et al., Pathway to a low carbon economy: energy systems modelling, in UKERC Energy 2050 Working Paper 1. November 2008. 2008, 13. Ramachandran, K., UK Markal model:

Documentation. Chapter 6. Residential Sector module, in Available at:

http://ukerc.ac.uk/ResearchProgrammes/EnergySystemsandModelling/ESMMARKALDocs08.aspx. 2008.

${ }^{4}$ The effect of taxation is much more relevant for the business sector.
} 
costs differ among different types of grid-connected PV systems within the UK PV market. Capital costs can change considerably from one type of application to another: different module technologies have different costs (e.g. thin film being generally cheaper that c-Si) and the various possible application types entail different mounting structures and other balance of system $(\mathrm{BOS})^{5}$ elements, which affect final system costs. It would also be ideal to use price figures coming from the UK PV market since direct conversion of PV system prices from e.g. other European countries can to some extent be misleading. In fact, prices (both at module and system level, i.e. including BOS costs) tend to differ between countries, not only due to currency conversion effects, but also because of different levels of market development and competition. For example, it is interesting to note the higher PV system price levels in the UK compared to the more developed PV market of Germany. The average UK cost for a standard roof top c-Si system is $£ 5,821 / \mathrm{kWp}$ (see Table 1 below) whereas in Germany, for example, system integrator SolarWorld quoted about $€ 4,500 / \mathrm{kWp}(£ 3,487)^{6}$ for a standard roof top c-Si PV system (in September 2007). Moreover, the installation and commissioning share of the total system price in the UK is about $19 \%$ versus $6.2 \%$ in Germany. The reasons behind such a spread are complex and beyond the scope of this work, but a more detailed analysis should be undertaken over a larger price sample to provide a robust explanation. However, provisional evidence seems to show that the smaller UK PV market, which would imply less competition as well as less market power for installers over input materials purchase (modules in particular), is likely to be a major cause of such differences [10, 15] (in addition to exchange rate effect).

However, obtaining UK-based, up to date and directly comparable quotes for each technology and PV system type considered has proven challenging ${ }^{7}$. As a result the initial capital cost figures used in the analysis comes from a variety of sources. Statistics on PV installations funded through the Low Carbon Building Programme Phase I (between April 2006 and February 2008) are the main source of $\mathrm{data}^{8}$. Investment cost figures per $\mathrm{kWp}$ are extrapolated

\footnotetext{
${ }^{5}$ Balance of system is intended to refer to all PV system components and cost elements except for the modules, thus also including mounting structures, cables and wiring, metering (for grid-connected applications) as well as installation, design and commissioning costs.

${ }^{6}$ Currency conversion all over this chapter are based on 2007 OECD Purchasing Power Prices for Euro area of $0.775 € / £$.

${ }^{7}$ Increasing confidentiality concerns, due to recent PV market growth and consequent higher market competition, has made industry representatives more sensitive to circulating price information. In fact, not all UK installers and industry representatives in other countries contacted were ready to openly provide price related information. In addition, the UK PV market is less developed than in other countries, so it was not possible to get UK-based data for PV module technologies not commercialised in the UK (like CIS).

${ }^{8}$ Such data are also averaged with up to date UK installer quotes (based on author's interviews with UK installers, 2007-2008)
} 
from the domestic PV installation dataset, for system sizes between $1.5-3 \mathrm{kWp}^{9}$. Table 1 provides an overview of such dataset.

Table 1. LCBP PV installations statistics

\begin{tabular}{ccccc}
\hline System type & PV tech. & $\begin{array}{c}\text { Average Cost - } \\
\text { £/kWp }\end{array}$ & $\begin{array}{c}\text { Average } \\
\text { size }\end{array}$ & $\begin{array}{c}\text { No. of } \\
\text { applications }\end{array}$ \\
\hline \hline \multirow{2}{*}{ Roof top } & $\mathrm{c}-\mathrm{Si}$ & $£ 5,821.7$ & 2.46 & 631 \\
& $\mathrm{a}-\mathrm{Si}(\mathrm{TJ})$ & $£ 3,929.2$ & 4.35 & 1 \\
PV tiles & $\mathrm{c}-\mathrm{Si}$ & $£ 8,105.6$ & 1.89 & 20 \\
Glass-glass & $\mathrm{c}-\mathrm{Si}$ & $£ 11,872.1$ & 0.68 & 1 \\
\hline
\end{tabular}

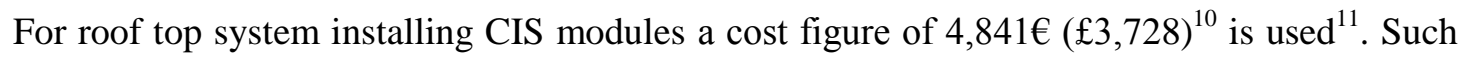
technology is not present in the dataset and still not widespread in the UK, so this figure is based on a September 2007 quote from Wurth Solar, a leading CIS module manufacturer also offering PV system solutions. However, this figure should be taken with caution as based on a single price quote.

\subsubsection{Low Carbon Building Programme (LCBP)}

The initial capital cost figures are net of the capital grant which a domestic PV owner would receive through the Low Carbon Building Programme (LCBP). The LCBP is a three years grant programme implemented in April 2006 to support installations of microgeneration technologies, including PV. The programme is divided in streams according to the type of project and applicant, i.e. households, business, community organizations and public. It constitutes the major PV specific policy incentive currently available in the UK. Household applicants are currently eligible for a maximum of $£ 2,000$ per $\mathrm{kW}$ of installed capacity, subject to an overall maximum of $£ 2,500$ or $50 \%$ of the relevant eligible costs, whichever is the lower [17]. The current grant level is much lower than what was initially offered to householders, i.e. $50 \%$ of the capital costs. Such lower grant level was in fact introduced in May 2007 in response to monthly funding allocations being insufficient to meet the then soaring demand for household PV grants $[18,19]$.

\footnotetext{
${ }^{9}$ Due to economies of scale, costs per kWp vary with system dimension, although such variations are relatively small within the size range of domestic PV systems. Cost figure relative to system size of around $4 \mathrm{kWp}$ is used for the only available a-Si "on roof" installation.

${ }^{10}$ Euros figures are converted in Pounds using OECD 2007 Purchasing Power Parity - PPP $£ / €=0.7716$. OECD, Puchasing Power Parities Data. http://www.oecd.org/dataoecd/61/54/18598754.pdf. Accessed on October 2008, 2008.

${ }^{11}$ This figure had been provided by the company as the price they would have applied to all European markets, including the UK.
} 


\section{$2.2 \quad$ Revenues}

Revenues cash flow depends on the amount of electricity produced by the PV system (system yield) and is a function of the electricity load profile of the PV owner, of conditions on reward to export as well as policy incentives. The following equation describes how revenues are calculated:

Revenues $=\alpha A I+\beta T G+\gamma E X$

$A I$ and $E X$ are respectively the avoided import and the electricity export calculated as a share of total electricity generated; $T G$ is the total generation; $\alpha$ is the electricity import tariff; $\beta$ is the unit value of a generation-based policy incentive (e.g. ROC price or feed-in tariff) or a generation-based reward to export tariff; $\gamma$ is the electricity export tariff.

The first term of the equation represents the value of the avoided import. This value depends on the import tariff and on the amount of generated electricity consumed locally, which varies according to different PV owners' load profiles. The matching of the electricity production of the PV system with the relative user load profile over time provides the measure of the amount of self-consumption and peak shaving versus electricity exported (see Section 2.2.2).

The second term is the value of the policy incentives considered, which applies to the total electricity generated. Generation-based policy incentives considered in this analysis are: Renewable Obligation Certificates (ROCs) and feed in tariffs (FITs) (see Sections 2.2.3 2.2.6). As further explained in Section 2.2.4, some of the reward to export currently offered to microgenerators by UK electricity suppliers are generation-based offers and the relative tariff also includes the value of ROCs (i.e. the value of the current main policy incentive). Thus, the parameter $\beta$ is the generation-based reward to export tariff when this type of reward is included in the analysis scenario.

The third term is the value of exported electricity, which depends on the amount of electricity actually exported to the grid (depending on the matching of PV generation with the end user's electricity load profile - see Section 2.2.2). This term of the equation becomes active when export based reward to export offers (see Section 2.2.4) are included in the analysis scenario. In such cases the cost of export meter installation is added to the initial capital cost, as UK PV installers usually only offer total generation meters as the default option [10,20]. 


\subsubsection{System yield}

The actual PV module performance is often different from specifications provided by manufacturers. Their power rating in fact refers to laboratory based "Standard Test Conditions" $" 12$, which in practice are rarely met in the real world. Real performance of a PV module is in fact quite site and system specific, as affected by temperature, cloud cover, light spectrum and other climatic conditions and can vary among different PV technologies [2125]. Moreover, PV system performance is highly affected by design and installation issue [2629].

A UK based study, the PV-Compare project, provides directly comparable data on actual PV module technologies performance under UK climate conditions [22-24, 30]. It provides halfhourly recording of meteorological conditions and the power generated by eleven different commercially available PV technologies (including crystalline silicon - c-Si, amorphous silicon - a-Si, Copper Indium Diselenide - CIS and Cadmium Telluride - CdTe) at two sites, one in the UK and one in Spain. The project has a strong consumer focus and performances are monitored at system rather than module level (accounting for necessary system level losses and adjustments). In terms of specific yields results show thin film technologies (in particular multijunction a-Si and CIS) better performing under high temperature due to intense lighting conditions (i.e. Spanish climate). They also have a good spectral response to blue light, found in diffuse lighting conditions, and consequently work better under overcast skies conditions (i.e. UK climate). An extract from the UK site results of the study is shown in Table 2; CIS and a-Si are found to outperform c-Si, due to the better response to UK climatic conditions.

Table 2. Summary of UK results from PV-Compare project

\begin{tabular}{c|c}
\hline PV tech & $\begin{array}{c}\text { Monitored annual } \\
\text { yield }(\mathbf{k W h} / \mathbf{k W p})\end{array}$ \\
\hline \hline a-Si (TJ) & 858.6 \\
$\mathrm{CIS}$ & 1025.3 \\
$\mathrm{c}-\mathrm{Si}$ & 847.1 \\
\hline Source: $[22]$
\end{tabular}

However, it must be said that this project, although still being unique in terms of direct comparability of different PV module technology performance under UK climate conditions, was undertaken in 1999. Since then, ongoing improvements in module technologies, PV systems design and installation as well as monitoring techniques make the project results

\footnotetext{
${ }^{12}$ Standard Test conditions are defined as: irradiance level of $1,000 \mathrm{Wm}-2$, spectral distribution of 1.5 and cell temperature of $25^{\circ} \mathrm{C}$
} 
somewhat out of date. Moreover, the outdoor performance of PV systems under varying climatic conditions is not fully understood yet. In fact, there is an increasing number of studies investigating outdoor performance of PV module technologies under varying climatic conditions [31-39] as well as ongoing research platforms focused on PV products performance and quality (such as "Performance", an integrated project financed by EU Commission [40]). However, results from existing contributions are not easily comparable as being either technology specific (e.g. performance of CIS modules at different locations), thus not allowing technologies comparison, or site specific thus not directly applicable to other climatic conditions, such as the UK one. Moreover, conversations with experts seemed to reveal that there still is a considerable level of discretion on how the monitored performance data are interpreted and presented.

Therefore, although it would be ideal to use annual yield figures differentiated according to module technologies installed and system types, and based on monitored performance data, for the purpose of this analysis a unique annual yield figure of $850 \mathrm{kWh} / \mathrm{kWp}$ for all target module technologies is used instead. Such a figure is in line with average annual electricity generation figures generally used in UK, such as in Energy Saving Trust reports which set it at $849.72 \mathrm{kWh} / \mathrm{kWp}[14,41]$. In addition, it has been demonstrated, using measured data coming from the monitoring of existing PV system operating within the UK that, for well designed PV systems, predicted annual yield is a good approximation of actually measured system performance $[20,26,42]^{13}$. Bahaj and James using monitored performance data from a PV system installed in Havant (Hampshire), report annual yields of 1300 for south facing arrays and $839.8 \mathrm{kWh} / \mathrm{kWp}$ for west facing ones [42]. J. Keirstead, using monitored performance data extrapolated from DTI Domestic Field Trial programme statistics, observes annual outputs in the $778-892 \mathrm{kWh} / \mathrm{kWp}$ range [20]. However, given the uncertainties in annual electricity output prediction above outlined, sensitivity analysis is done for this variable around the reference figure of $850 \mathrm{kWh} / \mathrm{kWp}$, using the range of annual yield figures as shown in Figure 70, i.e. from $675 \mathrm{kWh} / \mathrm{kWp}$ to $975 \mathrm{kWh} / \mathrm{kWp}$ [43]

\subsubsection{Electricity demand profile}

The typical UK household shows high electricity demand in the morning and in the evening hours, thus not coinciding with PV generation, which instead occurs during the day. This necessarily results in exporting an often consistent share of the total generation [42, 44]. However, electricity demand profiles and, in turn, import versus export scenarios can differ considerably between one end user and another. Within the domestic sector in particular

\footnotetext{
${ }^{13}$ Although it must be said that monitored performance data mainly come from systems installing c-Si module technologies, being the technologies that are most currently used in the UK.
} 
electricity demand depends on a variety of factors such as the number of household members, their ages, energy saving measures taken in each house, type of appliances, and lifestyle. Various studies have demonstrated the variation of electricity demand across types of households as a function of varying activity profiles [20, 42, 45]. Bahaj and James [42] for example have demonstrated that in a sample of nine identical houses the highest energyconsuming house typically use three times that of the lowest one. Moreover, they have identified three export scenarios for household generated electricity as function of different consumers' behaviours, which are used in the current analysis:

- High demand user: 25 per cent export

- Low demand user: 70 per cent export

- Typical user: 50 per cent export

Such shares are applied to total PV system generation to calculate the amount of generated electricity consumed locally - i.e. the avoided import- and the amount exported, for the three target consumption behaviours.

\subsubsection{Renewable Obligation Certificates}

The Renewable Obligation (RO) is the principal mechanism for supporting investments in renewables in the UK. Under the current mechanism, licensed electricity suppliers are obliged to source a given percentage of electricity from renewable sources. A Renewable Obligation Certificate (ROC) is awarded to renewable generators for each MWh of electricity generated. ROCs can be claimed only on an annual generation of 500kWh or more. Transaction costs often discouraged ROC claims from smaller generators [46]. As a consequence a series of measures have been taken to minimize complexity for microgenerators, such as the possibility to appoint agents to receive ROCs on their behalf or the introduction of a new IT system to simplify procedures [47]. Nevertheless, small generators still only account for less than $0.2 \%$ of the generating capacity and less than $0.05 \%$ of the ROCs issued in 2007-2008 [47].

RO has achieved a significant expansion of renewables capacity and succeeded in forcing renewables developers to take part in the electricity market [47]. However, the RO has not proven effective in achieving either the obligation targets set or the renewable technologies mix intended [48]. The RO has been designed to be technology neutral, hence all eligible renewable generators receive $1 \mathrm{ROC} / \mathrm{MWh}$ of renewable electricity generated irrespective of technology type. Such lack of differentiation between technologies has caused renewables investments to be biased in favour of more mature, less costly and risky technologies, such as onshore wind, co-firing and landfill gas. This bias has been particularly detrimental to 
photovoltaics which is characterised by higher capital costs compared to other renewable technologies. Recognising the need to make the RO more efficient and effective, the UK government has carried out three consultation exercises since October 2006 with the aim of reforming the RO. The main changes put forward by the reform are outlined in the latest Consultation [49] and in the government response document [50]. The major objectives of the proposed reform are:

- to provide more support to early-stage, more costly and risky renewable technologies (thus including PV);

- to provide greater confidence and certainty to investors about long-term policy commitment;

- to minimize complexity for microgenerators.

The reform would entail, among other things, the award of more or less than one ROC for each MWh generated, depending on the stage of development of each technology (Banding). $\mathrm{PV}$ would be allocated in the highest band, for emerging technologies, thus being eligible for two ROCs per MWh generated.

The price of ROCs is market driven. This paper cannot fully describe the complexity of RO and ROC price formation, but what is relevant for the current analysis is the fact that ROC price varies with time and it is significantly dependent on the level of underlying renewable generation (high levels of generation produce low prices and vice versa). The discounted cash flow analysis requires revenue projections into the future for the whole life time of the PV system and thus a price curve for ROCs is necessary. A model developed by Robert Kesterson [5] is therefore used to estimate the price curve for ROCs under the current RO regime as well as under the proposed RO reform.

\subsubsection{Reward to export}

Although the market for exported generation is still in its infancy, as a result of the Climate Change and Sustainable Energy Act ${ }^{14}$ suppliers are now offering a quite wide range of tariffs and conditions to electricity export purchase [51]. They can be divided in three main categories:

\footnotetext{
${ }^{14}$ The Climate Change and Sustainable Energy act 2006 is a Parliament Act aimed at increasing the microgeneration in the UK. Under the terms of the Act, among other things, The Secretary of State has been granted powers to modify the supply and distribution licences in order to require suppliers to acquire electricity generated by microgeneration by their own customers. 
1. Metered offers: here the tariff offered applies only to the electricity exported to the grid. The PV system owner is in fact required to install an export meter. This implies an additional cost as UK PV installers usually offer only total generation meter (which only measures the total PV system production) as a default option ${ }^{15}$. Such export tariff does not generally include the price for ROCs, which is then claimed autonomously by the PV system owner. However, Scottish Power and Scottish Southern Electric ask to their customers (and PV system owners) to be appointed as ROC agent for their generation and the relative revenues are included in the tariff they offer.

2. Generation based offers: the major difference from the previous category is that here the tariff offered is applied on the total electricity generated by the system instead of only the share of generated electricity exported to the grid. The export meter installation is therefore not required. Such type of tariff also includes ROCs price, with the suppliers acting as third agent for the PV system owner.

3. Unmetered offers: These types of offer are independent from metered electricity flows. In some cases they are applied to exported electricity only, but on the basis of export volume estimates; in other cases an annual fixed amount is offered per $\mathrm{kWp}$ installed.

Table 3 summarizes the range of tariffs and reward to export arrangements offered by UK suppliers to domestic customers (source: [51] plus interviews with UK suppliers, March 2008).

Table 3. Reward to export tariffs

\footnotetext{
${ }^{15}$ Based on the author's interviews of UK installers, 2007-2008.
} 


\begin{tabular}{|c|c|c|}
\hline & $\begin{array}{l}\text { Export } \\
\text { Tariff } \\
\text { p/kWh }\end{array}$ & $\begin{array}{l}\text { Export } \\
\text { Meter } \\
\text { Installation } \\
\text { Cost - £ } \\
\end{array}$ \\
\hline \multicolumn{3}{|l|}{ 1. Metered offers } \\
\hline British Gas & 5 & 30 \\
\hline $\mathrm{EDF}$ & 7.64 & $70-200$ \\
\hline nPower & 11.64 & 60 \\
\hline E-on & $8.79-11.26$ & 100 \\
\hline \multicolumn{3}{|l|}{ Including ROCs } \\
\hline Scottish Power & 4.25 & free \\
\hline Scottish Southern El. & 18 & free \\
\hline \multicolumn{3}{|l|}{$\begin{array}{l}\text { 2. Generation based } \\
\text { offers }\end{array}$} \\
\hline EDF & 5 & NA \\
\hline Ecotricity & 4.5 & NA \\
\hline Good Energy & 9 & NA \\
\hline \multicolumn{3}{|l|}{ 3. Unmetered offers } \\
\hline $\begin{array}{l}\text { British Gas - } \\
\text { EcoSave }\end{array}$ & \multicolumn{2}{|l|}{$£ 18$ per year } \\
\hline EDF - Green Tariff & \multicolumn{2}{|c|}{$£ 10$ per $\mathrm{kW} /$ per year } \\
\hline N Power & \multicolumn{2}{|c|}{$\begin{array}{l}\text { Same as in } 1 . \text {, but paid on } \\
\text { assumed export equal to } 50 \% \\
\text { of generation }\end{array}$} \\
\hline E-on -Solarnet & $\begin{array}{l}\text { Same as in } \\
\text { volume es } \\
\text { customer chat }\end{array}$ & $\begin{array}{lr}\text { 1., but } & \text { export } \\
\text { mated } & \text { from } \\
\text { cteristics } & \end{array}$ \\
\hline
\end{tabular}

\subsubsection{Import tariff}

The import tariffs also show a degree of variability among suppliers, regions as well as customer choice and consumption. Average import tariffs for each supplier are inputted in the analysis. They vary between 9.54 $\mathrm{p} / \mathrm{kWh}$ and $12.27 \mathrm{p} / \mathrm{kWh}$ [51].

\subsubsection{Feed in Tariff (FIT)}

The basic FIT is a mandated long term premium price for renewable energy, usually differentiated by technologies used and size of installation. Such payment is guaranteed over a long term period which usually covers a significant proportion of the working life of the installation. It is a form of renewables support which has been enacted in many countries and regions in the recent years ${ }^{16}$ and strong momentum for FIT continues around the world with many countries implementing new FIT tariffs or revising the exiting ones [53]. Many of these new FIT implemented are specifically directed at PV as in the case of Italy, France, Greece and Portugal. Implementation of FIT has clearly fostered investment and interest in renewables in many countries. An often quoted example is the dramatic PV market expansion in Germany due to the revision in 2004 of the German feed-in law (EEG) [2, 54-56]. Many advocates of FIT argue that such a scheme is the most cost effective, producing the quickest renewable technologies deployment at the least cost [55, 57-63]. Such argument is mainly based on the consideration that, with respect to obligation/quota schemes, a FIT scheme provides the investor with a secure medium term basis for investment planning which reduces investment risk and therefore the cost of capital. This brings down the cost of investing in renewables and increases market confidence for manufacturers, generators and investors. Moreover, FIT seems to better encourage small scale renewables with respect to quota schemes, such as Renewable Obligation [57, 61]. This paper

\footnotetext{
${ }^{16}$ In 2007 at least 37 countries and 9 states/provinces around the world had adopted such policy. 52. REN 21, Renewables 2007. Global Status Report. Renewable Energy Policy Network for the 21st Century, 2007.
} 
cannot go into the details of the pros and cons of FIT versus quota schemes or in the details of different FIT design options. The aim here is to provisionally assess what would be the impact of FIT introduction in the UK on the profitability of investing in PV systems. A provision calling on government to implement a system of feed-in tariffs for small renewable energy producers by 2010 has been introduced in the recently approved Energy Bill ${ }^{17}$. The feed-in tariff scheme will run in parallel to the reformed Renewables Obligation with the major aim of encouraging smaller scale renewables. Discussion on the type and rates of the tariff scheme has only just started, thus it is not yet clear what kind of FIT scheme will actually be implemented in the UK [64]. The details of operation will be the subject of a government consultation during summer 2009 [50].

For the purpose of this analysis a fixed price (generation-based) mechanism [60, 65, 66] is assumed for both domestic and business sector applications, designed with a base tariff level of $£ 0.35$ and 20 years duration. Such a tariff level is the sterling equivalent of the average base rate offered in other European countries (about $€ 0.45)^{18}$ and is in line with figures used in other UK-based studies [41, 67]. However, FIT schemes for PV technologies do generally differentiate for system type and size, to account for electricity generation costs variations according to location, application and plant size. In fact, a properly designed FIT scheme should be technology and application specific in order to guarantee the right level of remuneration to the investment. Such differentiation is not explicitly accounted for in this analysis, which is instead run for a range of tariff levels to assess how the level of remuneration changes among the different PV system type for varying tariff levels. The tariff level is assumed to range between $£ 0.35 / \mathrm{kWh}$ and $£ 0.60 \mathrm{kWh}$. A properly designed FIT scheme should also include tariffs degression, which however does not need to be factored into this analysis. In fact degression applies on a year on year basis while this analysis assesses PV system investment profitability within a given year.

\section{The analysis}

The financial viability of investing in the selected PV system applications is assessed for two set of scenarios. The first set aims at providing a picture of profitability and incentives to invest in the targeted PV systems under current UK market, technical and regulatory conditions. The second set looks at the role of policy and potential future technological

\footnotetext{
${ }^{17} \mathrm{http}: / /$ services.parliament.uk/bills/2007-08/energy.html

${ }^{18}$ Currency conversion is based on 2007 OECD Purchasing Power Prices for Euro area of $0.77 € / £$.
} 
development by exploring the impact of alternative policy instruments and technology cost reductions on the financial viability of investing in photovoltaics.

Two "current" scenarios are identified:

- First "no reward to export" is assumed. In this case revenues come only from the savings on the electricity bill, i.e. the avoided import.

- Then the impact on PV systems profitability of the introduction of different reward to export tariff options is assessed. In this case, the third element of equation (1) is "active" and reward to export is added to the stream of revenues.

The aim is to assess the different tariff arrangements currently available to PV domestic owners against the three consumer behaviour and export scenarios identified in Section 2.2.2, with the objective of maximizing the PV owner's financial benefits.

The impact on PV system profitability of changes in currently available policy support is then explored in the second set of scenarios. In particular the following policy changes are assessed and compared:

- LCBP change introduced in May 2007;

- The RO reform;

- Introduction of a fixed price, generation based, FIT.

The aim is to assess the effectiveness of the proposed policy changes in the deployment of PV technologies within the UK electricity sector.

Finally, cost reduction scenarios for the PV technologies considered are also developed and the relative impact on financial viability of PV system investments is explored.

\subsection{No reward to export}

This case assumes no reward to export. The revenues from PV system come from the savings on the electricity bill, i.e. the value of the avoided import, and from ROCs ${ }^{19}$. The third element of equation (1) is equal to zero. Any electricity exported to the grid is basically "lost". In this case load shifting to match generation profile can help in maximising the revenues from PV generation, as other studies have already demonstrated [42, 44].

\footnotetext{
${ }^{19}$ Assuming that the typical domestic PV owner actually claim ROCs, which, on the basis of the evidence provided by the author's interviews of UK installers, seems to be a realistic assumption.
} 


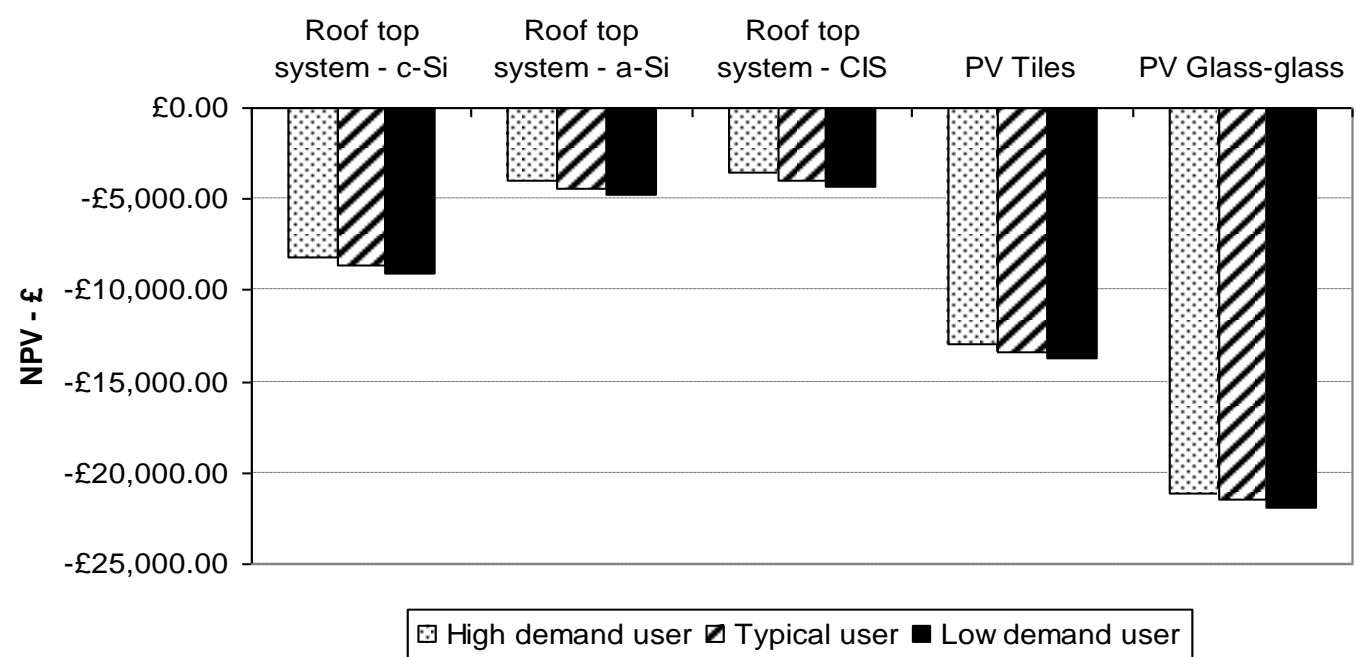

Figure 1. No reward to export scenario results

Results show that under no reward to export PV system investments are not financially attractive for households (Figure 1). In fact, NPVs result all negative, and well below $£$ 10,000 for PV tiles and glass-glass due to much higher capital costs. However, among standard on roof PV systems, CIS technology shows the highest NPV, due to its lower initial capital costs. Higher demand users show better NPV results, due to the lower export/higher avoided import. This confirms that, under no reward to export, PV system owners have strong incentives to maximise local consumption of generated electricity.

\subsection{Reward to export}

The reward to export element is here added to the stream of revenues. The export tariff options offered by UK suppliers as shown in Table 3 are not always easily comparable. Moreover, the actual impact on the economics for PV system owners is likely to change according to their electricity consumption behaviour, i.e the relative share of avoided import versus export. The analysis therefore assesses how the profitability of the investment would change according to the different tariffs arrangement ${ }^{20}$ for the three consumer export scenarios identified. The cost of export meter installation is added to the initial capital cost when metered offers are considered.

\footnotetext{
${ }^{20}$ Unmetered offers are not included in the analysis as less convenient and often transitory, i.e. offered while waiting for export meter installation.
} 


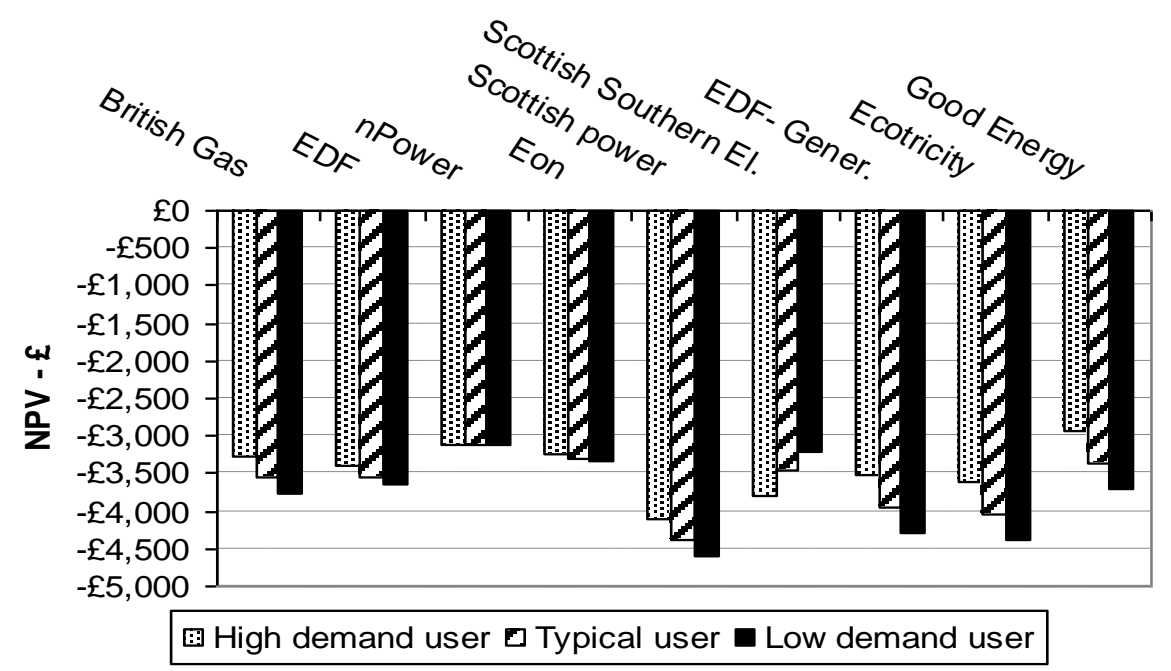

Figure 2. Reward to export scenario results

Even in the presence of reward to export, investing in PV system remains unattractive for UK households (Figure 2). Results are shown for a roof-top - CIS system, which on average shows the highest NPV, although still negative (-£3,621 versus $-£ 8,350$ for c-Si and $-£ 4,056$ for a-Si). However, the results show that the choice of reward to export arrangement can affect the profitability of the investment and that such impact changes according to the PV system owner's electricity consumption profile. In fact, unlike in the "no reward to export" case, high demand users are not always better off in this case. In presence of a very high export tariff, such as the one offered by Scottish Southern Electric, low demand users show a higher NPV, i.e. it is more convenient to export electricity than consume it locally. In all other cases, high demand users are better off, apart from the case of nPower, which has set import and export tariffs to the same level, therefore making irrelevant the split between avoided import and export (in equation (2), in Section 7.2.2, $\boldsymbol{\alpha}$ and $\boldsymbol{\gamma}$ are equal). The worst option for all three consumer behaviours is Scottish Power, which offers the lowest tariff. The best option varies: for typical and low demand users it is nPower; for high demand user it is Good Energy. It should be noted that reward to export tariffs used in this analysis reflects a given point in time and are subject to change over time. Comparison between specific company offerings should be treated with caution.

\subsection{Policy incentives}

From a pure financial point of view, a positive NPV is necessary (although not sufficient) condition for an investment to be attractive. The analysis above has shown this is not the case for domestic PV system in the UK, under current technological development, market and 
regulatory conditions. The impact on PV system profitability of reformed or alternative policy incentives is therefore here considered. In particular each of the following policy changes is assessed:

- the impact of an higher capital grant, as provided by the LCBP before the changes introduced in May 2007;

- the impact of Renewable Obligation reform, in particular the introduction of Banding, which would make PV eligible for two ROCs;

- Introduction of a fixed price, generation based FIT for the following range of tariff rates: $£ 0.35 / \mathrm{kWh}, £ 0.40 / \mathrm{kWh}, £ 0.50 / \mathrm{kWh}, £ 0.60 / \mathrm{kWh}$.

The "no reward to export" scenario for the "typical user" is used as baseline. Results are shown in Figures 3 and 4 below (PV tiles and glass-glass are not included in the graph as NPV results are too low).

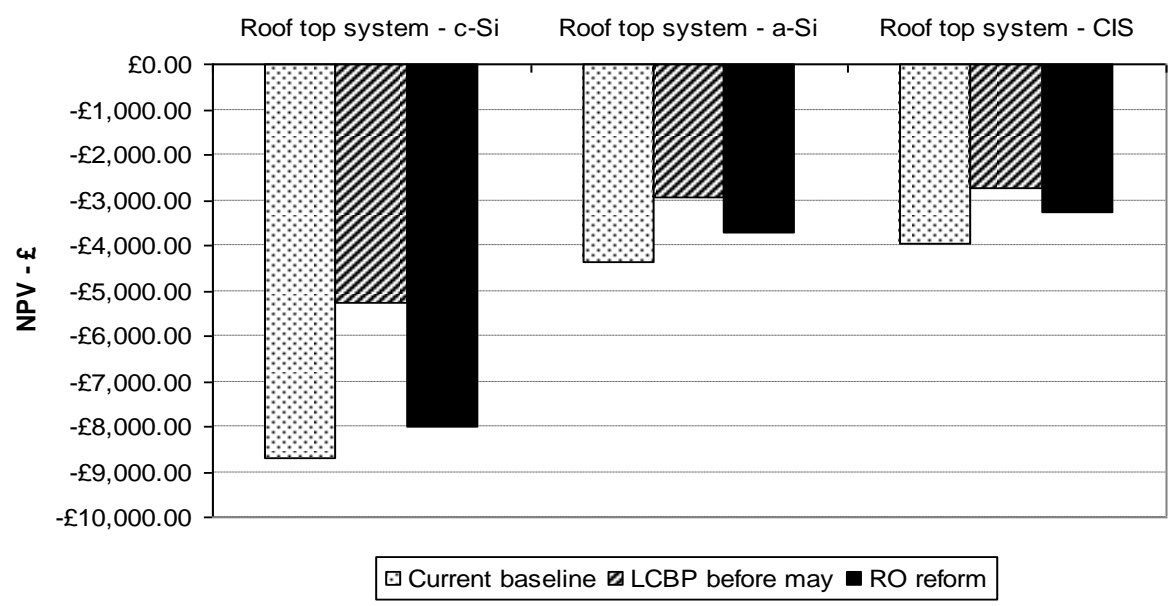

Figure 3. Impact of $L C B P$ change and $R O$ reform

None of the PV systems considered was profitable even when the previous higher LCBP grant (i.e. before May 2007) is considered (Figure 3). Still, NPVs improve considerably with respect to the current grant level scenario (middle bars). The reduction in initial capital grant has therefore made the investment less attractive to UK householders, which are now even more discouraged by the initial high upfront cost. Interviews with UK installers have in fact provided evidence of a sharp decrease in demand for domestic PV systems due to this change. This impact is also evident when looking at statistics on PV installations funded through the Low Carbon Building Programme. The total number of applications has dropped from 487 in the first year $(4 / 06-3 / 07)$ to 430 in the second year (5/07 - 5/08). In addition, the average installation size has decreased. The combined drop in installation size and number of new 
installations has led to a drop in overall installed capacity of $45 \%$, from 1,439 to $749 \mathrm{kWp}$ [15].

The introduction of banding as a consequence of RO Reform doubles the revenues from ROCs therefore increasing the profitability of PV systems. NPVs in fact increase for all PV systems, although still remaining negative (black bars in Figure 3). Therefore, the RO reform aim of increasing the appeal for early-stage, more costly and risky renewable technologies might not be fully achieved for domestic PV systems.

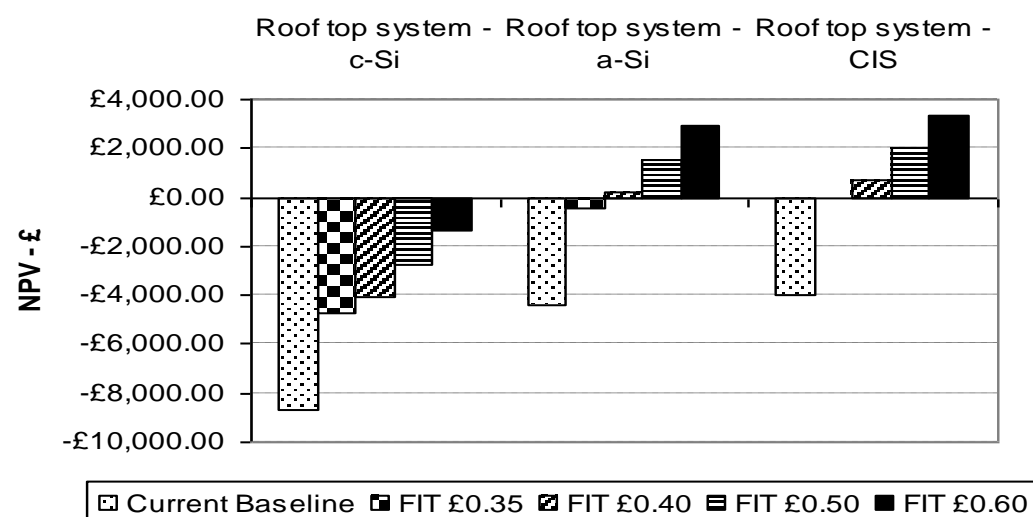

Figure 4. FIT implementation. Results for a range of possible tariff levels

The only policy alternative that would make investment profitable is the introduction of a FIT as an alternative to ROCs (Figure 4). Standard roof top systems installing a-Si and CIS show positive NPVs for tariff levels between $£ 0.40$ and $£ 0.60$. For these PV system investments payback periods ${ }^{21}$ range between respectively 8 and 7 years under a $£ 0.60$ tariff and 20 and 15 years under $£ 0.40$. These results are mainly due to the higher level of the FIT versus ROC price per $\mathrm{kWh}$ generated. The impact of lower investment risk and cost of capital on NPV under FIT versus RO is not factored into the analysis. However, even for a high level of feedin tariff only investments in PV systems installing CIS and a-Si module technologies (i.e. the cheaper technology options) become profitable. This suggests that high initial capital costs are still the major issue.

It must be said that, theoretically, the results could to some extent be different if other not easily quantifiable benefits of PV systems were be included in the analysis, e.g. increase in property value. This is a quite important point as in the last years there has been an increasing

\footnotetext{
${ }^{21}$ Payback period is defined as the number of periods it takes for a project to recover cost outlays.
} 
policy interest and commitment toward improving energy building performances. This is seen by many as one of the main drivers in the UK for the deployment of building integrated microgeneration technologies, including PV [68, 69]. The implementation of the EU Energy Performance of Building Directive through the Energy Performance Certificates system and tighter "Code for Sustainable Homes" (CSH) as well as the requirement for local authorities to adopt the "Merton rule" and specify energy efficiency standards are examples of such regulations. However, quantifying the impact of these regulations on the financial viability of PV system investments is not straightforward. One possibility would be to estimate the potential property value increase due to the higher energy performance of the building/house. However, apart from some anecdotal evidence ${ }^{22}$, interviews with UK developers did not provide sufficient evidence to back such argument with a robust dataset. Moreover, it will probably take several years from implementation before such regulations will start having a quantifiable impact on the housing market.

\subsection{Sensitivities}

To assess the validity of the NPV results presented above sensitivity analysis was carried out on the most important input parameters and assumptions. Figure 5 shows the results of a $15 \%$ increase in each assumption. The "no reward to export" scenario for the typical user is here used as a baseline.

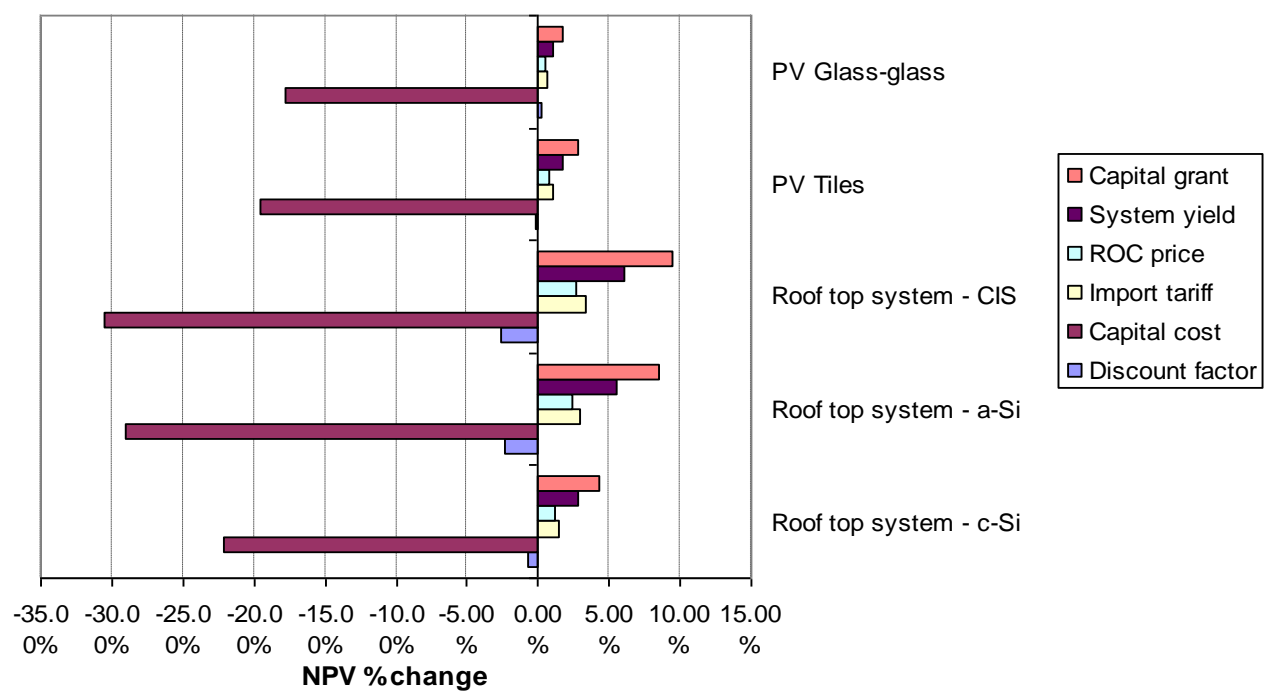

Figure 5. NPV per cent change to 15 per cent increase in relevant assumptions

\footnotetext{
22 "The three-bed townhouses with C21e solar tiles sold at a premium of $8.6 \%$ " http://www.spongenet.org/library/Gleeson\%20Homes\%20case\%20study.pdf
} 
An increase in capital costs has the highest -negative- impact on NPVs, showing how costs are the major element affecting investment profitability. Additional evidence in support of this is the relatively high impact on NPV of an increase in capital grant, which would thus decrease the initial capital cost burden. Discount rates have a higher and negative impact on systems which display lower initial capital costs, as the relative weight of future revenues stream versus costs is higher in such cases (thus a higher discounting of such revenues has a higher impact on final NPV) ${ }^{23}$. For the same reason, increases in all the other three variables (ROC price, Import tariff and System yield, which all affect revenues stream) have higher impact on NPVs for systems with lower initial capital cost.

Sensitivity analysis is also done for some of the more uncertain input assumptions, by using specific ranges of figures ${ }^{24}$ :

- On the discount rate, for values ranging around the reference of 12 per cent.

- On system yield, for values ranging between $675 \mathrm{kWh} / \mathrm{kWp}$ and $975 \mathrm{kWh} / \mathrm{kWp}$.

Results in Figures 6 and 7 show a rather limited impact on NPVs, absolute levels of changes in energy yield and discount rates, thus indicating that other factors and, in particular, initial capital costs currently play the major role in defining systems profitability in the domestic sector.

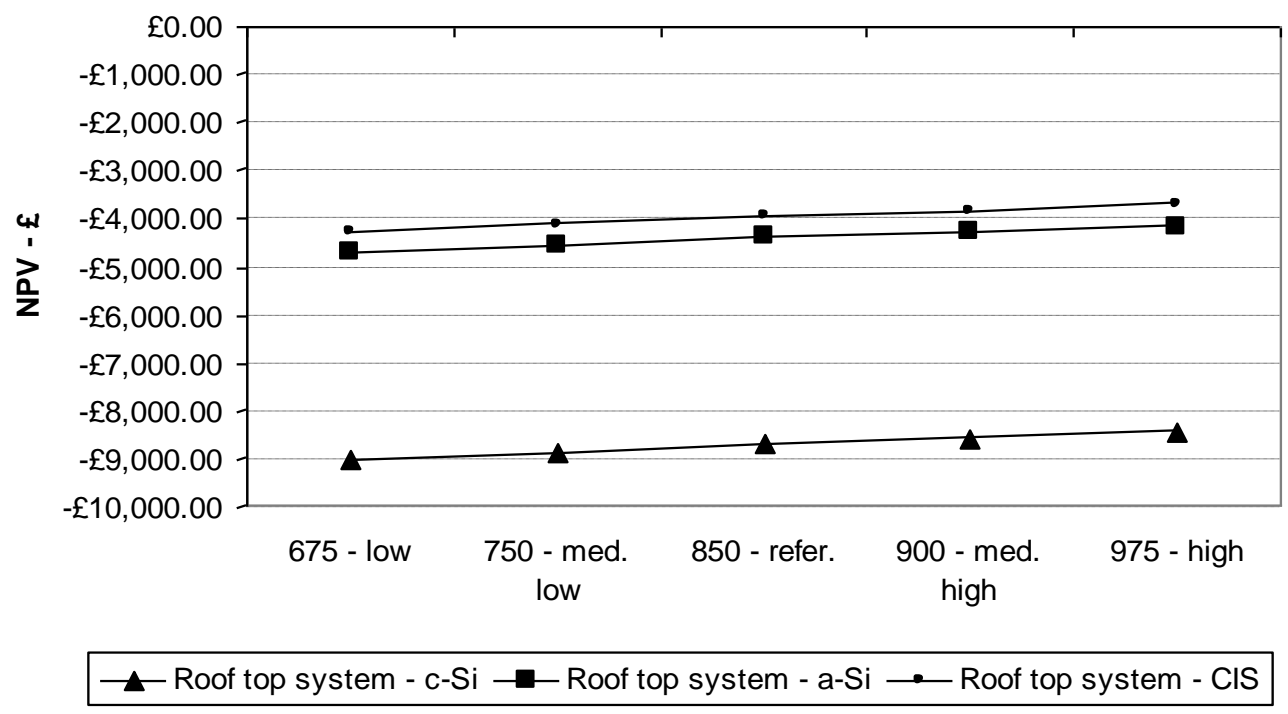

Figure 6. Sensitivity of NPV to energy yield

\footnotetext{
${ }^{23}$ Note that an increase in the discount rate has a slightly positive impact on PV glass-glass system, as in such cases the relative weight of costs versus revenues is heavily skewed toward costs, leading to higher levels of NPV for increasing discount rates (i.e. higher discounting of costs has a positive impact on NPV value).

${ }^{24}$ The "no reward to export" scenario for the typical user is used as reference case.
} 


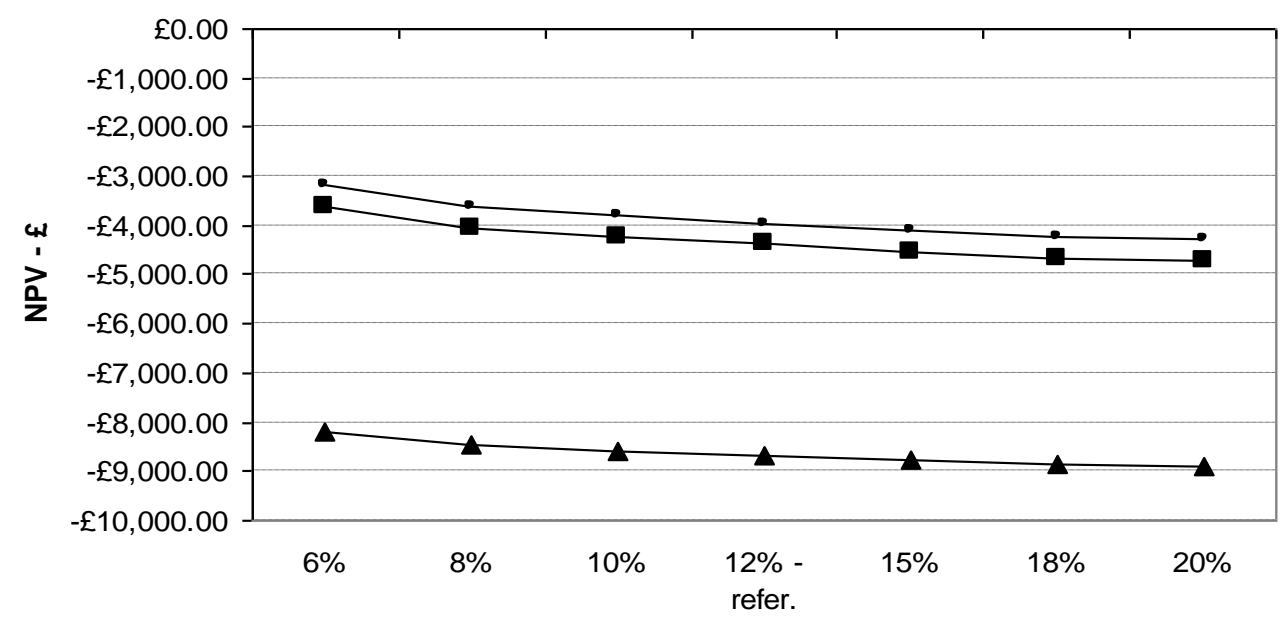

Roof top system - c-Si $\rightarrow$ - Roof top system - a-Si $\longrightarrow$ Roof top system - CIS

Figure 7. Sensitivity of NPV to discount rate

However, it is interesting to notice that the impact of system yield variation on NPV is much higher in the presence of a FIT of e.g. £0.50, as shown in Figure 8 (when compared to Figure 6). This result points out the importance of PV system performance and its impact on the profitability of the investment. Particularly in the presence of output based policy incentives such as FIT, it is crucial to have a well performing system in place in order to optimise investment profitability.

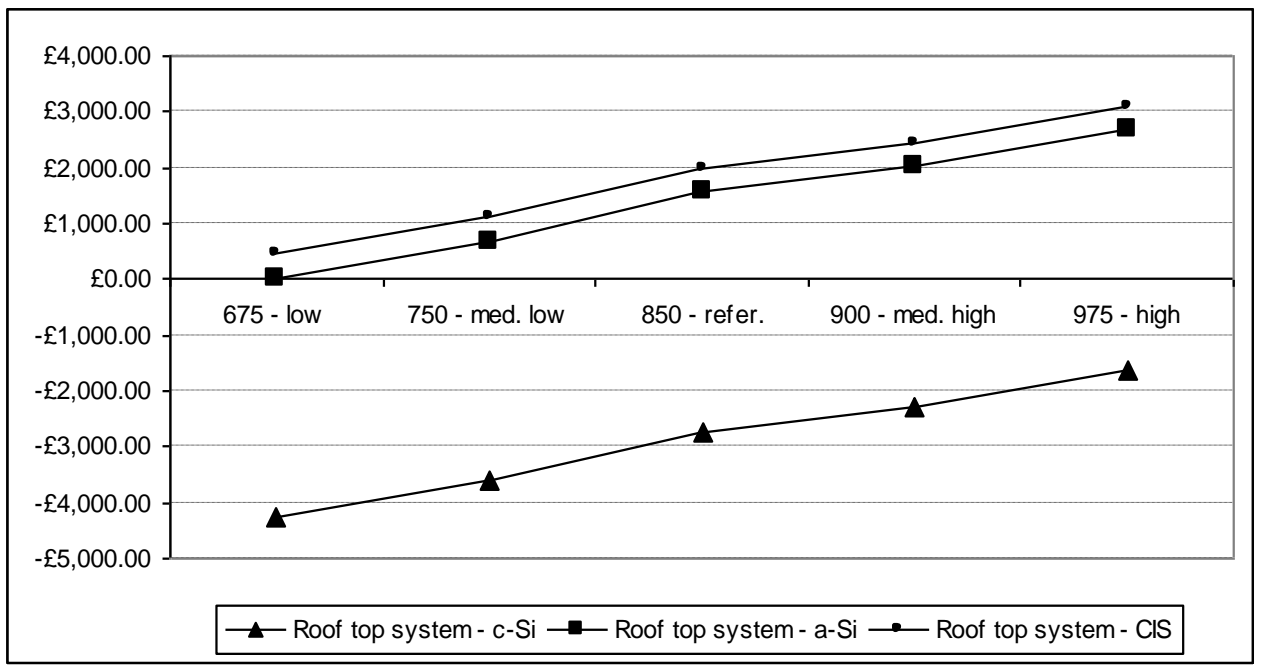

Figure 8. Sensitivity of NPV to System yield, in presence of a FIT of £0.50 
In conclusion, the analysis to date has shown that initial capital costs currently have the major impact on the profitability of PV systems in the UK. This has been shown by the impact of the LCBP change as well as being clearly evident in the sensitivity analysis.

\subsection{Cost reductions}

As costs are such a relevant element in the overall financial appraisal, the impact of expected cost reductions on NPV is now assessed. High costs are generally recognised as the main barrier for PV deployment and a lot of academic research and industry efforts are focusing on this clear priority. Among the various contributions, the EU PV Technology Platform provides target cost reductions at the module and system level (i.e. including BOS cost reductions) for each technology generation. Their target cost reduction figures are introduced into the analysis to assess how the profitability of PV systems would change if such targets were actually achieved. Table 4 shows the figures used in the analysis for standard roof-top systems.

Table 4. PV cost reductions for standard roof top systems installing $c$-Si and thin film module technologies

\begin{tabular}{|c|c|c|}
\hline \multicolumn{3}{|l|}{ Modules and BOS target costs $-\epsilon / W p$} \\
\hline & 2013 & 2020 \\
\hline$c-S i$ module $-€ / W p$ & 1.35 & 0.75 \\
\hline a-Si module (glass substrate) - $€ / W p$ & 0.95 & 0.65 \\
\hline CIGS module - $€ / W p$ & 1 & 0.8 \\
\hline BOS - rooftop systems - $€ / W p$ & $0.9-1.1$ & $0.75-0.9$ \\
\hline
\end{tabular}

TOTAL COST at System level - $£ / W p^{*}$

\begin{tabular}{l|cc}
\hline & $\mathbf{2 0 1 3}$ & $\mathbf{2 0 2 0}$ \\
\hline \hline c-Si roof top $-\mathfrak{f} / \mathbf{W p}$ & 1.81 & 1.23 \\
a-Si roof top $-\mathfrak{f} / \mathbf{W p}$ & 1.50 & 1.16 \\
CIGS roof top $-\mathfrak{f} / \mathbf{W p}$ & 1.54 & 1.27 \\
\hline
\end{tabular}

* Sum of module and BOS target costs. Euros figures are converted to Pounds using OECD 2007 Purchasing Power Parity

Source: Author elaboration, [16, 70].

Such figures should be taken as indicative, given the existing uncertainties surrounding cost reductions estimation both at module and BOS level. Moreover, the figures are converted from Euros to Pounds using OECD Purchasing Power Parity, which is only an approximation of what UK prices will actually be in the future. In fact, as outlined in Section 2.1, system prices tend to differ between countries, not only due to currency conversion effects, but also 
because of different levels of market and competition developments, which are less easy to predict. Nonetheless, they provide a good indication of where PV costs might get to.

Results are shown in Figure 9, where the "no reward to export" scenario for the typical user is used here as a 2008 baseline.

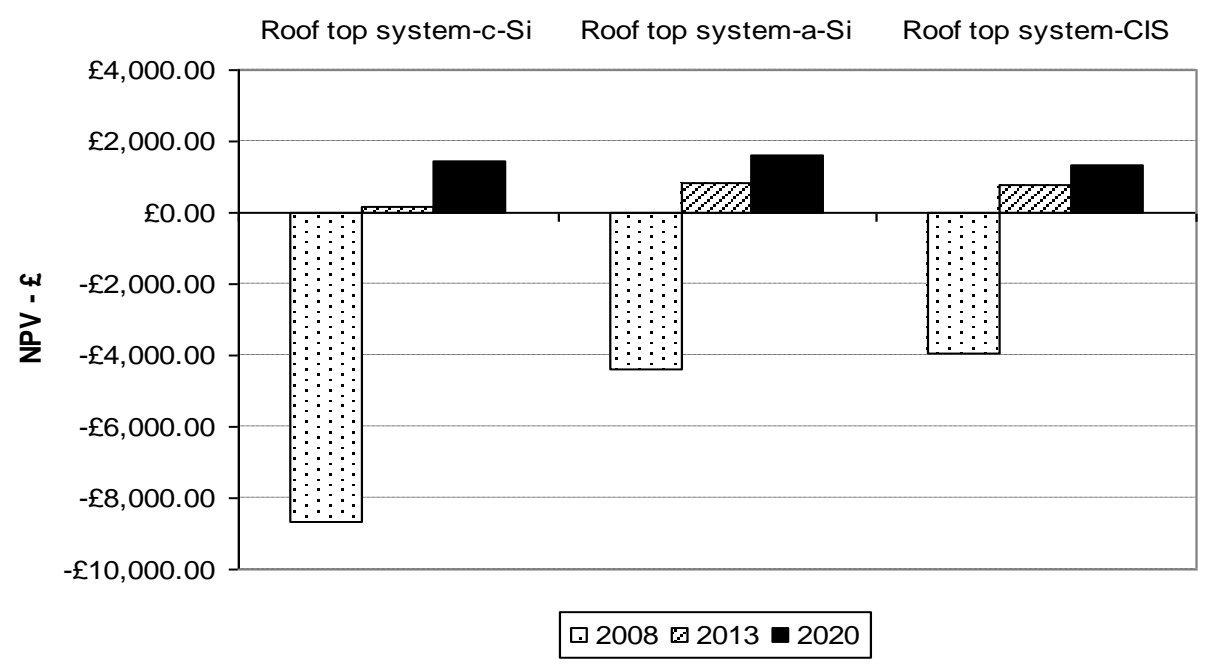

Figure 9. Impact on profitability of cost reductions in 2013 and 2020

According to the results, standard roof top PV systems would become profitable by 2013, if the target cost reductions were actually achieved. Payback time of the investment would be 8 years for roof top systems installing c-Si in 2013, and below 5 years for the c-Si system in 2020 and for the other two systems both in 2013 and 2020.

\section{Conclusions and discussion}

Domestic PV investments are generally not profitable under current cost, market and regulatory conditions. However, despite the currently unattractive financial prospects of PV systems, the domestic sector analysis has shown that a PV owner's electricity demand profile and reward to export conditions do matter in the financial appraisal of a domestic PV system. In particular, when PV owners are not rewarded for their export (a situation that was very common in the UK until few years ago) they have strong incentives to maximise local consumption of generated electricity. In other words, they have to match their consumption profile with their PV generation profile as much as possible. As discussed in Section 2.2.2 the typical UK household shows an electricity demand profile which does not generally coincide with PV generation. This would result in high levels of exported electricity whose value 
would be lost for the PV owner in the absence of a reward to export. In this scenario load shifting (such as changing the time of dishwashers or washing machine use) is the optimal behavioural response for the maximization of PV financial benefits [44, 71]. However, UK PV owners can now choose among a range of reward to export offers from electricity suppliers. It is interesting to note how PV owner incentives can change in the presence of reward to export. For example, with a high export tariff they can be better off by exporting generated electricity than consuming it locally. Considering that load shifting and changes in consumption behaviour can in reality be constrained by culture and lifestyle, results indicate that PV owners should choose the reward to export (and ROCs arrangement) option with care and on the basis of their own expected electricity consumption profile.

Capital costs are currently an overwhelming element in the financial appraisal of PV system options causing revenue-related factors to have little impact on systems profitability. Thus, an overarching conclusion of this analysis is that cost reductions are greatly needed to increase the appeal of PV systems in the UK. The analysis has shown how standard roof top PV systems could become a profitable investment by 2013 if targeted cost reductions did actually occur, both at module and balance of system (BOS) level. The likelihood of achieving such targets depends on a series of worldwide PV sector developments, including R\&D and industry efforts as well as future market trends and governments support. However, it is important to note that while module and system components cost reductions depend on worldwide R\&D and industry efforts, initial evidence have shown how system level cost reductions (i.e. including BOS) need to be achieved at a national level, mainly through national PV market expansion ${ }^{25}[73,74]$. This has to be taken into account in interpreting the results of this analysis, as the BOS and system level cost reductions assumed are not UK specific, but rather are an expression of average EU potential. In fact, they are calculated by accounting for BOS cost reduction potential in countries such as Germany, i.e. already experiencing higher PV market expansion and lower system level cost than the UK. In other words, in order for the UK to be able to reach the system level cost reductions assumed in this analysis a stronger than current baseline expansion of the national PV market should also be assumed.

The analysis has shown how the current policy framework is not enough to make PV systems financially viable. The combination of Renewable Obligation Certificates and Low Carbon Building Programme capital grants is not enough to make domestic PV systems a profitable

\footnotetext{
${ }^{25}$ BOS cost reductions are attributed to greater system integration and the growing experience of system designers and installers, which in turn is often related to the level of development of the relative national PV market

72. Harmon, Experience curves of photovoltaic technology, in IR 00-014, IIASA, Laxenburg, Austria. 2000.
} 
investment. Moreover, the reduction of the Low Carbon Building Programme capital grant in May 2007 has made domestic PV investment even less attractive and has severely affected domestic PV deployment.

The two ROCs provision for emerging technologies included in the RO Reform is not sufficient to make most PV systems profitable. Therefore, in the case of PV technologies, the reform is likely to fail in one of its main intended aims: increasing the deployment of early stage, more costly and risky renewable technologies (including PV). The only policy alternative that would make PV system investment profitable in the UK, given current PV system cost levels, is the introduction of a FIT scheme, in alternative to RO. Of the PV system options considered those installing a-Si and CIS modules display positive NPVs for tariff levels equal or above $£ 0.40 / \mathrm{kWh}$. The more expensive c-Si PV system options do not become profitable even for the highest tariff rate considered. This on one hand suggests that high initial capital costs are still a major issue and on the other hand that the FIT levels should possibly be set above $£ 0.35$, if policy makers' intention is to design a UK FIT scheme which would guarantee a reasonable return on PV investments.

In conclusion, the analysis results show how PV technologies are unlikely to reach high penetration levels in the UK unless consistent cost reductions are achieved and/or further government support implemented. Nevertheless, the future of PV technologies in the UK may be brighter than the current baseline. More stringent planning and building regulations are likely to benefit PV penetration since, compared to other microgeneration technologies, PV requires no additional space and can be easily integrated into building fabrics [68]. In addition, and perhaps more importantly, the UK government commitment toward the introduction of feed-in tariffs for small renewable energy producers by 2010 is going to increase financial attractiveness of PV investments, thus it is likely to benefit PV deployment. Moreover, FITs scheme have an additional advantage, not directly quantifiable in this analysis, but nonetheless important. FITs implies certainty of future revenues, as the support is guaranteed for a fixed level and for a given period of time. This reduces investment risks and can facilitate access to credit and the development of innovative forms of financing for PV investments ${ }^{26}$. As already introduced in Section 2, the successful introduction of FITs in other countries has in fact fostered the creation of PV-dedicated credit lines and soft loan programmes which have helped in overcoming the major capital costs barrier and helped the deployment of PV technologies.

\footnotetext{
${ }^{26}$ See also Section 2.2.6.
} 


\section{REFERENCES}

1. EPIA - European Photovoltaic Industry Association and Greenpeace, Solar generation V - 2008. Solar electricity for over 1 billion people and 2 million jobs by 2020 . EPIA Report, 2008.

2. Jager-Waldau, A., PV Status report 2008. Joint Research Centre, Renewable Energy Unit. EUR 23604 EN - 2008, 2008.

3. Infield, D., A road map for photovoltaics research in the UK, in UKERC Research $\begin{array}{lll}\text { Report. } & \text { August } & \end{array}$ http://ukerc.rl.ac.uk/Roadmaps/Solar/A Road Map for Photovoltaics Research in the UK. pdf. 2007.

4. Ernst \& Young, Impact of banding the Renewable Obligation - Costs of electricity production. 2007, DTI.

5. Kesterton, R., Market support mechanisms and investment risk: will the Renewable Obligation allow offshore wind to meet its potential in the UK? MSc Dissertation, 2007.

6. Szabo', S. and A. Jager-Waldau. Increasing the share of photovoltaics - is it an obstacle or imminent for a competitive European electricity market? in 21st European Photovoltaic Solar Energy Conference. 2006. 4-8 September 2006, Dresden, Germany.

7. Watson, J., et al., Unlocking the power house: policy and system change for domestic micro-generation in the UK, in University of Sussex, University of Southampton, Imperial College London. 2006.

8. Hausman, J.A., Individual Discount Rates and the Purchase and Utilization of EnergyUsing Durables. The Bell Journal of Economics, 1979. 10(1): p. 33-54.

9. Coller, M. and M.B. Williams, Eliciting individual discount rates. Experimental Economics, 1999. 2: 107-127.

10. Pers. Com. with UK installers, 2008.

11. Bank of England, Statistical Interactive Database - Interest \& exchange rates data in Available

http://www.bankofengland.co.uk/mfsd/iadb/index.asp?Travel=NIxIRx\&levels=1\&C=DQY\&C=K $\mathrm{T} \& \mathrm{C}=5 \mathrm{TT} \& \mathrm{C}=\mathrm{E} 30 \& \mathrm{C}=\mathrm{E} 76 \& \mathrm{C}=\mathrm{E} 7 \mathrm{~B} \& \mathrm{C}=\mathrm{E} 80 \& \mathrm{C}=\mathrm{DUS} \& \mathrm{~A} 4062 \mathrm{XBMX} 4051 \mathrm{X} 4052 \mathrm{X} 4053 . \mathrm{X}=5 \& \mathrm{~A}$ 4062XBMX4051X4052X4053. $y=8 \&$ FullPage $=X 4051 \& F u l l P a g e H i s t o r y=X 4051 \&$ Nodes $=X 4051$ X4052X3687X3691X4053X4058\&SectionRequired=I\&HideNums=-1\&Extralnfo=true\#BM. Accessed: March 2009. 2009.

12. Anandarajah, G., et al., Pathway to a low carbon economy: energy systems modelling, in UKERC Energy 2050 Working Paper 1. November 2008. 2008.

13. Ramachandran, K., UK Markal model: Documentation. Chapter 6. Residential Sector module, in Available at: http://ukerc.ac.uk/ResearchProgrammes/EnergySystemsandModelling/ESMMARKALDocs08. aspx. 2008. 
14. Energy Saving Trust, Econnect, Elementenergy, Potential for microgeneration. Study and analysis. Final Report. 2005.

15. Jardine C. and N. Bergman. The status of the UK domestic PV market - A review of the impact of the Low Carbon Building Programme. in PVSAT - 5. Photovoltaic Science Applications and Technology. 1-3 April 2009. 2009. Glyndwr University.

16. OECD, Puchasing Power Parities http://www.oecd.org/dataoecd/61/54/18598754.pdf. Accessed on October 2008, 2008.

17. Low Carbon Building Programme, http://www.lowcarbonbuildings.org.uk/home/. 2008.

18. Elliot, F., Ministers suspend solar power grants. The Indipendent, 2007. 25 March 2007.

19. Seager, A., Thinking of going green at home? - you'd better start getting up early. The Guardian, 2007. 7th February 2007.

20. Keirstead, J., Behavioural responses to photovoltaic systems in the UK domestic sector, in Thesis submitted to the University of Oxford for the degree of Doctor of Philosophy. 2006.

21. Durisch, W., et al., Efficiency model for photovoltaic modules and demonstration of its application to energy yield estimation. Solar Energy Materials and Solar Cells, 2007. 91(1): $p$. 79-84.

22. Jardine C., Lane K. PV-COMPARE: Relative Performance of Photovoltaic Technologies in Northern and Southern Europe. in PV in Europe Conference and Exhibition. 2002. Rome.

23. Jardine C., Conibeer G.J., Lane K. . PV-Compare: Direct Comparison of Eleven PV Technologies at Two Locations in Northern and Southern Europe. in 17th European Conference on Photovoltaic Solar Energy Conversion. 2001. Munich.

24. Jardine C., Lane K., Photovoltaics in the UK: An Introductory Guide For New Customers, in Environmental Change Institute, Report 27. University of Oxford. 2003.

25. McSharry, P.E., Assessing photovoltaic performance using local linear quantile regression, in Energy power systems, W. Tayati, Editor. 2006, ACTA press.

26. Pearsall, N.M., K.M. Hynes, and M. Munzinger. Performance analysis of domestic PV systems in the UK: results from the domestic field trial in PVSAT - 3. Photovoltaic Science Applications and Technology. 2007. Durham.

27. Jardine, C.N. Performance of west Oxfordshire district council office's photovoltaic arrays. in PVSAT - 3. Photovoltaic Science Applications and Technology. 2007. Durham.

28. Ransome, S. How accurate can PV energy yield simulations be? in Photovoltaic science applications and technology - PVSAT 4. 2008. Bath, 2-4 April 2008.

29. Balouktsis, l., et al. Optimized inverter sizing in the UK. in Photovoltaic Science Applications and Technology - PVSAT 4. 2008. Bath, 2-4 April 2008.

30. Climate Change and Sustainable Energy Act. http://www.opsi.gov.uk/ACTS/acts2006/ukpga 20060019 en 1. 2006. 
31. Cameron, C.P., W.E. Boyson, and D.M. Riley. Comparison of PV system performance-model predictions with measured PV system performance in 33rd IEEE Photovoltaic Specialists Conference. 2008. San Diego, 11-16 May 2008.

32. del Cueto, J.A., et al. Stability of CIS/CIGS modules at the outdoor test facility over two decades. in 33rd IEEE Photovoltaic Specialists Conference. 2008. San Diego, 11-16 May 2008.

33. Jansen, K.W., S.B. Kadam, and J.F. Groelinger. The advantages of amourphous silicon photovoltaic modules in grid-tied systems. in IEEE 4th World conference on Photovoltaic Energy Conversion. 2006. Hawaii, May 7-12 2006.

34. Makrides, G., B. Zisser, and G.E. Georghiou. Outdoor efficiency of different photovoltaic systems installed in Cyprus and Germany. in 33rd IEEE Photovoltaic Specialists Conference. 2008. San Diego, 11-16 May 2008.

35. Nikolaeva-Dimitrova, M., , Kenny, R.P., Dunlop E.P. . Long-term stability of a-Si:H thin film modules. in 21st European Photovoltaics Solar Energy Conference. 2006. Dresden, DE.

36. Ransome, S. A summary of outdoor testing and modelling of PV systems. in 3rd Photovoltaic Science Applications and Technology Conference (PV SAT). 2007. Durham, 2830 March 2007.

37. Ruther, R., et al. Performance test of amorphous silicon modules in different climates - year four: progress in understanding exposure history stabilization effects. in 33rd IEEE Photovoltaic Specialists Conference. 2008. San Diego, 11-16 May 2008.

38. Spena, A., C. Cornaro, and S. Serafini. Outdoor test facility for advanced technologies PV modules. in 33rd IEEE Photovoltaic Specialists Conference. 2008. San Diego, 11-16 May 2008.

39. UNI-SOLAR, United Solar Ovonic, Technical Report, in Available online at http://www.uni-solar.com/uploadedFiles/AA53606-02Technical\%20Report120706small.pdf. 2006.

40. Performance, A science base on PV performance for increased market transparency and customer confidence Integrated Project (IP) funded by the European Commission under FP6. , 2009. http://www.pv-performance.org/performance (accessed on January 2009).

41. Energy Saving Trust, Generating the future: an analysis of policy intervention to achieve widespread microgeneration penetration, in EST Report. November 2007. 2007.

42. Bahaj, A.S. and P.A.B. James, Urban energy generation: The added value of photovoltaics in social housing. Renewable and Sustainable Energy Reviews, 2007. 11(9): p. 2121-2136.

43. Joint Research Centre, Photovoltaic Geographical Information System (PVGIS). Geographical Assessment of Solar Resource and Performance of Photovoltaic Technology. EU Commission. Joint Research Centre, Institute for Energy, Renewable Energy Unit. Available online at: http://re.jrc.ec.europa.eu/pvgis/, 2009. 
44. Kreutzer, N., G.H. Beyer, and I. Knight. The modulation of electric load profiles in domestic dwellings by BIPV and options to maximise the load match - An Investigation for the United Kingdon. in PVSAT - 3. Photovoltaic Science Applications and Technology. 2006. Durham.

45. Lampaditou, E. and M. Leach, Evaluating participation of residential customers in demand response programs in the UK, in ECEEE Summer Study, Vol 3, pp. 1271-1282, F. Bartiaux and A.G. Salnaes, Editors. 2005, Mandelieu, France: European Council for an Energy Efficient Economy.

46. DTI-Ofgem, Distributed energy. A call for evidence for the review of barriers and incentives to distributes electricity generation, including combined heat and power, in A joint Government-Ofgem review. 2006.

47. Ofgem, Renewable Obligation: annual report 2007-2008, in Ofgen Annual Report. Ref: 17/09. March 2009. 2009.

48. Ofgem, Reform of the Renewable Obligation 2006: Ofgem's response. Response to Government consultation, 2007.

49. BEER, Statutory Consultation on the renewable Obligation Order 2009, in Reform of the Renewable Obligation. Department for Business Enterprice \& Regulatory Reform. June 2008. 2008.

50. DECC, Government Response to the Statutory Consultation on the Renewables Obligation Order 2009, in Reform of the Renewable Obligation. Department of Energy and Climate Change (DECC). December 2008. 2008.

51. Ofgem, Review of the market for exported electricity from microgeneration, in Ofgem report. 11 March 2008. 2008.

52. REN 21, Renewables 2007. Global Status Report. Renewable Energy Policy Network for the 21st Century, 2007.

53. REN 21, Renewables Global Status Report. 2009 Update. Renewable Energy Policy Network for the 21st Century, 2009.

54. Bode, S. and H. Groscurth, Incentives to invest in electricity production from renewable energy under different support schemes, in Arrhenius Institute for Energy and Climate Policy Report. Hamburg. March 2008. 2008.

55. Mendonca, M., Feed-in Tariffs. Accelerating the deployment of renewable energy, ed. World Future Council. 2007, London: Earthscan.

56. Rickerson, W. and R.C. Grace, The debate over fixed price incentives for renwable electricity in Europe and the United States: fallout and future directions, in A white Paper prepared for The Heinrich Boll Foundation. February 2007. 2007.

57. Farrell, J., Minnesota Feed-In Tariff could lower cost, boost renewables and expand local ownership. The New Rules Project. Policy Brief, 2008.

58. Toke, D., Making the UK renewables programme FITTER. World Future Council Report, 2007. 
59. L.E.K. Consulting, Policy frameworks for renewables. Analysis on policy framewroks to drive future investment in near and long-term renewable power in the UK. Carbon Trust, London, 2006.

60. Lesser, J.A. and X. Su, Design of an economically efficient feed-in tariff structure for renewable energy development. Energy Policy, 2008. 36(3): p. 981-990.

61. Toke, D., Renewable financial support systems and cost-effectiveness. Journal of Cleaner Production, 2007. 15(3): p. 280-287.

62. Mitchell, C., D. Bauknecht, and P.M. Connor, Effectiveness through risk reduction: a comparison of the renewable obligation in England and Wales and the feed-in system in Germany. Energy Policy, 2006. 34(3): p. 297-305.

63. Ofgem, Ofgem's response to BERR consultation on reform of the Renewables Obligation. Response to government consultation, 2007.

64. Johnson, R., Solar industry launches campaign for feed-in tariff support. New Energy Focus (online), 2009. 2nd February 2009 (available at: http://newenergyfocus.com/do/ecco.py/view item?listid=1\&listcatid=32\&listitemid=220 1\&section=On-site $\% 20 \% 26 \% 20 \mathrm{Micro}$ ).

65. del Río, P. and M.A. Gual, An integrated assessment of the feed-in tariff system in Spain. Energy Policy, 2007. 35(2): p. 994-1012.

66. Klein, A., et al., Evaluation of different feed-in tariff design options - Best practice paper for the International Feed-in Cooperation, in Fraunhofer ISI. Energy Economics Group. December 2006. 2006.

67. Element Energy, The growth potential for on-site renewable electricity generation in the non domestic sector in England, Scotland and Wales, in Commissioned by Departmenr for Business Enterprice \& Regulatory Reform. September 2008. 2008.

68. Element Energy and Energy Saving Trust, The role of onsite energy generation in delivering Zero Carbon Homes. A report from the Renewable Advisory Board, 2007(November 2007).

69. Ofgem, Review of distributed generation, in A joint Government/Ofgem Report. May 2007. 2007.

70. EU PV Technology Platform, A strategic research agenda for photovoltaic solar energy technology, in Research and development in support of realising the "Vision for photovoltaic technology". Prepared by Working Group 3 "Science, technology and Applications" of the EU PV Technology Platform 2007.

71. Keirstead, J., Behavioural responses to photovoltaic systems in the UK domestic sector. Energy Policy, 2007. 35(8): p. 4128-4141.

72. Harmon, Experience curves of photovoltaic technology, in IR 00-014, IIASA, Laxenburg, Austria. 2000.

73. Schaeffer, G.J., et al., Photovoltaic experiences. Synthesis report of the Photexproject, in ECN publications http://www.ecn.nl/en/ps/research-programme/energyinnovation/photex/publications/. 2004. 
74. Wiser, R., G. Barbose, and C. Peterman, Traking the sun. The installed cost of photovoltaics in the U.S. from 1998-2007, in Lawrence Berkeley National Laboratory. February 2009. 2009. 